\title{
Measurement of kyphosis and vertebral body height loss in traumatic spine fractures: an international study
}

\author{
Said Sadiqi ${ }^{1}$ - Jorrit-Jan Verlaan ${ }^{1} \cdot$ A. Mechteld Lehr ${ }^{1} \cdot$ Jens R. Chapman $^{2}$ • \\ Marcel F. Dvorak $^{3}$ - Frank Kandziora ${ }^{4}$ - S. Rajasekaran ${ }^{5}$ Klaus J. Schnake ${ }^{6}$. \\ Alexander R. Vaccaro ${ }^{7}$ F. Cumhur Oner ${ }^{1}$
}

Received: 31 March 2016/Revised: 25 July 2016/Accepted: 25 July 2016/Published online: 6 August 2016

(C) The Author(s) 2016. This article is published with open access at Springerlink.com

\begin{abstract}
Purpose To investigate whether wide variations are seen in the measurement techniques preferred by spine surgeons around the world to assess traumatic fracture kyphosis and vertebral body height loss (VBHL).

Methods An online survey was conducted at two time points among an international community of spine trauma experts from all world regions. The first survey (TL-survey) focused on the thoracic, thoracolumbar and lumbar spine, the second survey (C-survey) on the subaxial cervical spine. Participants were asked to indicate which measurement technique(s) they used for measuring kyphosis and VBHL. Descriptive statistics, frequency analysis and the Fisher exact test were used to analyze the responses.
\end{abstract}

Said Sadiqi

s.sadiqi-3@umcutrecht.nl

1 Department of Orthopaedics, University Medical Center Utrecht, HP G05.228, P.O. Box 85500, 3508 GA Utrecht, The Netherlands

2 Swedish Neuroscience Institute, Swedish Medical Center, Seattle, WA, USA

3 Department of Orthopaedics, University of British Columbia, Vancouver, BC, Canada

4 Center for Spinal Surgery, BGU-Hospital, Frankfurt, Germany

5 Department of Orthopaedic and Spine Surgery, Ganga Hospital, Coimbatore, India

6 Center for Spinal Surgery, Schön Klinik Nürnberg Fürth, Fürth, Germany

7 Department of Orthopaedics, Thomas Jefferson University, Philadelphia, PA, USA
Results Of the 279 invited experts, 107 (38.4\%) participated in the TL-survey, and 108 (38.7\%) in the C-survey. The Cobb angle was the most frequently used for all spine regions to assess kyphosis (55.6-75.7 \%), followed by the wedge angle and adjacent endplates method. Concerning VBHL, the majority of the experts used the vertebral body compression ratio in all spine regions (51.4-54.6\%). The most frequently used combination for kyphosis was the Cobb and wedge angles. Considerable differences were observed between the world regions, while fewer differences were seen between surgeons with different degrees of experience.

Conclusions This study identified worldwide variations in measurement techniques preferred by treating spine surgeons to assess fracture kyphosis and VBHL in spine trauma patients. These results establish the importance of standardizing assessment parameters in spine trauma care, and can be taken into account to further investigate these radiographic parameters.

Keywords Kyphosis - Vertebral body height loss . Radiographic measurement · International survey · Spine trauma

\section{Introduction}

A significant proportion of major trauma patients suffer spine injuries, which can contribute to disability with longterm consequences and associated health related costs. Epidemiological studies have reported annual incidences of traumatic spine fractures between 19 and 88 per 100,000 population $[1,2]$. The reported annual incidence of spinal cord injured patients varies from 13.9 to 19.4 per million population in Europe, and 43.3-51.0 in North America 
[3-5]. In the trauma setting as well as during follow-up, different clinical and radiological parameters are taken into account by the treating surgeons as a guide to decide on treatment strategy. Clinical parameters may include patients' neurological status as a critical indicator, and injury morphology [6-9]. Also radiographic measurements are crucial, including sagittal alignment (kyphosis) and the amount of vertebral body height loss (VBHL) [10-12]. Changes in the kyphotic angle may indicate the degree of instability of the injured spinal segment and progression of deformity. Increasing VBHL has the potential to contribute to and enhance this instability, which can result in changes in the treatment plan. In the thoracolumbar spine, various studies have shown a kyphotic angle of $15^{\circ}-30^{\circ}$ or VBHL of more than $50 \%$ to be associated with instability [13-16].

Different measurement techniques have been described to assess these radiographic parameters. It is not known which specific measurement technique, or combination of techniques, is preferred by spine surgeons around the world. We hypothesize that different measurement techniques are used to assess fracture kyphosis and vertebral body height loss. The use of different techniques could result in different measurements and thereby lead to treatment variability for certain types of spine fractures [17-19]. Moreover, the use of a standardized technique would facilitate a universal language, both in research and clinical settings. Therefore, the aim of the current study is to investigate whether wide variations are seen in the measurement techniques preferred by spine surgeons around the world to assess traumatic fracture kyphosis and vertebral body height loss in both the thoracolumbar spine and the cervical spine.

\section{Materials and methods}

\section{Study design}

A cross-sectional web-based survey was conducted at two time points, with an interval of 3 months, among spine surgeons from all world regions (Asia Pacific, Europe and Sub Saharan Africa, Latin America, Middle East and North Africa, and North America).

\section{Recruitment of participants}

The recruitment of potential participants was performed through AOSpine International. As it was aimed to include a worldwide sample of surgeons experienced in spine trauma care, an international pool of 279 experts from the AOSpine and International Spinal Cord Society (ISCoS) was identified. They could only participate if they were an orthopedic-, trauma- or neurosurgeon with at least 5 years of experience in the treatment of adult spine trauma patients. Also fluency in English was required to complete the surveys. The current survey was combined with two surveys of an AOSpine project that focuses on the development of a surgeon reported outcome instrument for spine trauma patients [20, 21].

\section{Survey instrument}

The first survey (TL-survey) focused on the measurement techniques in the thoracic (T1-T10), thoracolumbar (T11L2) and lumbar spine (L3-L5), while the second survey (Csurvey) focused on the subaxial cervical spine (C3-C7). In the first part of both surveys, participants were asked about their professional background. In the second part, they were asked to indicate which measurement technique(s) they used to assess fracture kyphosis and VBHL. The surveyed measurement techniques were based on the previously described Radiographic Measurement Manual of the Spine Trauma Study Group [22], and included five techniques for measuring fracture kyphosis and two methods for VBHL. Participants could indicate whether they use one specific technique, a combination of techniques, some other technique or do not measure that spinal parameter. The response option 'another technique' required a specification. At the end, free text fields were provided for any general comments. All data were recorded and analyzed anonymously.

\section{Surveyed measurement techniques kyphosis}

As shown in Fig. 1, the five surveyed methods to measure fracture kyphosis were: (1) 'Cobb angle', from the superior endplate of the adjacent cranial vertebral body to the inferior endplate of the adjacent caudal body (bisegmental angle); (2) 'Gardner's method', using the superior endplate of the vertebral body above and inferior endplate of the fractured vertebral body (monosegmental angle); (3) 'posterior walls angle', measuring the angle between the posterior walls of the vertebral bodies above and below the injured vertebra; 4) 'adjacent endplates method', from the inferior endplate of the vertebra above and the superior endplate of the vertebra below the fracture; and (5) 'wedge angle', measuring from the superior endplate to the inferior of the injured vertebra.

\section{Surveyed measurement techniques VBHL}

The two surveyed methods for measuring VBHL were (see Fig. 2): (1) Anterior/Middle Column Vertebral Body Compression Ratio ('VBCR'), i.e. the ratio of anterior vertebral height $(\mathrm{AVH})$ to posterior vertebral height $(\mathrm{PVH})$ 
Fig. 1 Surveyed measurement techniques for assessing fracture kyphosis. Method 1 Cobb angle (bisegmental), Method 2

Gardner's method

(monosegmental), Method 3

posterior walls angle, Method 4

adjacent endplates method,

Method 5 wedge angle

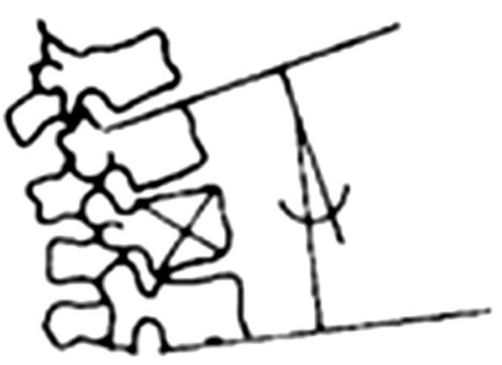

Method 1

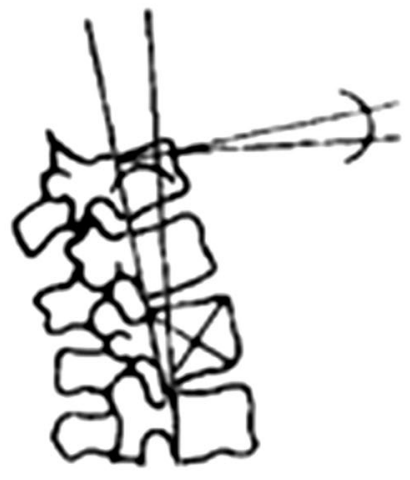

Method 3

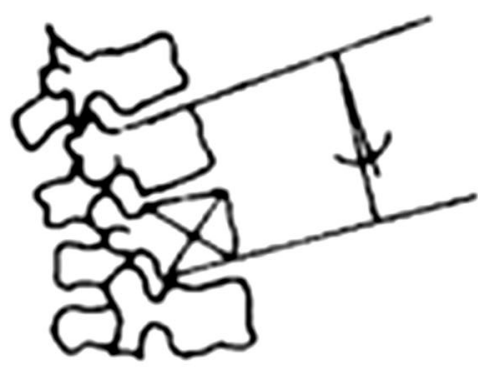

Method 2

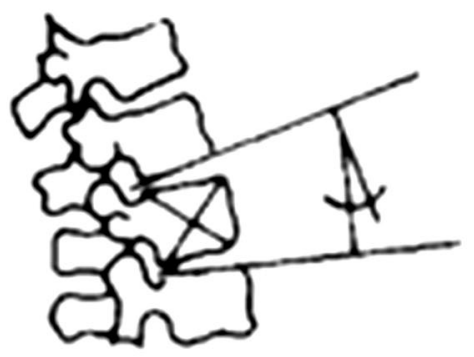

Method 4

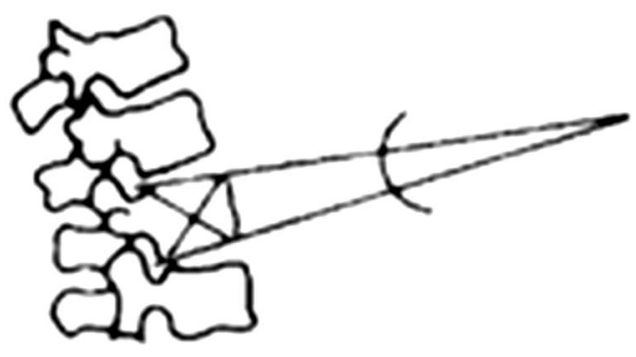

Method 5

with the formula VBCR $=\mathrm{AVH} / \mathrm{PVH}$; and (2) the Anterior Vertebral Body Compression Percentage ('AVBC \%'), consisting of the percentage of anterior vertebral body compression with respect to the average height of the anterior vertebral bodies immediately cephalad and caudad to the injury level (formula: $V 2 /[(V 1+V 3) / 2] \times 100 \%)$.

\section{Statistical analysis}

Descriptive statistics were used to analyze the characteristics of the participants. For each measurement technique, absolute and relative frequencies along with their $95 \%$ confidence interval were calculated for the different spine regions. If a combination of techniques was indicated by an expert, each technique was counted independently. Hence, with relative frequencies being analyzed relative to the total number of participants, the sum of relative frequencies could exceed $100 \%$. Descriptive statistics and the Fisher exact test (significance level $\alpha=0.05$ ) were used to analyze any differences between the five world regions, and the influence of clinical experience $(\leq 10,11-20$ or $>20$ years). 
Table 1 Characteristics of surveyed experts

\begin{tabular}{lll}
\hline & TL-survey $(n=107)$ & C-survey $(n=108)$ \\
\hline Male $(\%)$ & $104(97.2 \%)$ & $107(99.1 \%)$ \\
Age, mean \pm SD (range) in years & $46.6 \pm 8.2(30-67)$ & $47.1 \pm 8.0(30-65)$ \\
AOSpine world region $(\%)$ & & \\
Asia Pacific & $24(22.4 \%)$ & $23(21.3 \%)$ \\
Europe/Sub Saharan Africa & $29(27.1 \%)$ & $28(25.9 \%)$ \\
Latin America & $30(28.0 \%)$ & $28(25.9 \%)$ \\
Middle East/North Africa & $10(9.3 \%)$ & $12(11.1 \%)$ \\
North America & $14(13.1 \%)$ & $17(15.7 \%)$ \\
Profession (\%) & & $35(32.4 \%)$ \\
Neurosurgeon & $35(32.7 \%)$ & $65(60.2 \%)$ \\
Orthopaedic surgeon & $63(58.9 \%)$ & $8(7.4 \%)$ \\
Trauma surgeon & $6(5.6 \%)$ & 0 \\
Other & $3(2.8 \%)$ & $96(88.9 \%)$ \\
Spine fellowship completed (\%) & $84(78.5 \%)$ & $98(90.7 \%)$ \\
Main working field $(\%)$ & & $7(6.5 \%)$ \\
Clinic & $98(91.6 \%)$ & 0 \\
Education & $4(3.7 \%)$ & 0 \\
Management & $2(1.9 \%)$ & $17.1 \pm 8.4(5-40)$ \\
Research & $1(0.9 \%)$ &
\end{tabular}

$T L$-survey first survey focusing on the thoracic, thoracolumbar and lumbar spine

C-survey second survey focusing on the subaxial cervical spine
Fig. 2 Surveyed measurement techniques for assessing vertebral body height loss. Method 1 anterior/middle column vertebral body compression ratio $(\mathrm{VBCR})=\mathrm{AVH} / \mathrm{PVH}$, Method 2 anterior vertebral body compression percentage $(\mathrm{AVBC} \%)=V 2 /[(V 1+V 3) /$ 2] $\times 100 \%, A V H$ anterior vertebral height, $P V H$ posterior vertebral height

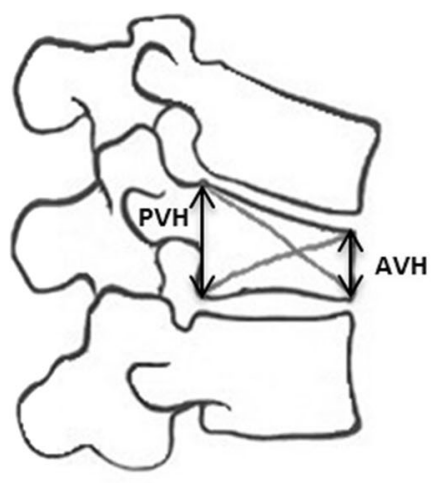

Method 1

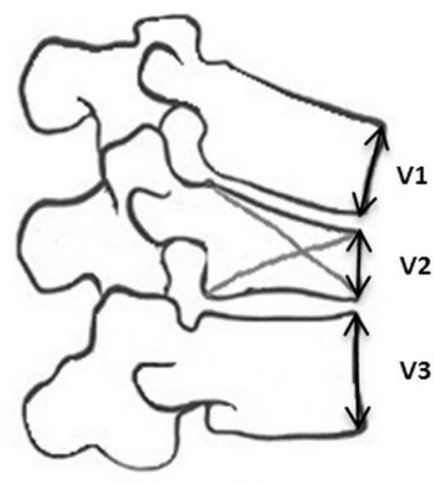

Method 2
Method $1=$ Anterior/Middle Column Vertebral Body Compression Ratio $($ VBCR $)=$ AVH $/ \mathrm{PVH}$

Method $2=$ Anterior Vertebral Body Compression Percentage (AVBC\%) $=$ V2 $/[(V 1+V 3) / 2] \times 100 \%$

$\mathrm{AVH}=$ anterior vertebral height

$\mathrm{PVH}=$ posterior vertebral height

\section{Results}

\section{Response rate}

Out of 279 invited experts, 107 (38.4\%) from 43 different countries participated in the first survey (TL-survey), and
$108(38.7 \%)$ from 41 different countries in the second survey (C-survey). The number of experts that participated in both surveys was $64(22.9 \%)$. Comparable socio-demographic characteristics and results were observed between this group and the total number of participants from each survey. To have a larger number of participants 
Table 2 Results for the assessment of fracture kyphosis

\begin{tabular}{|c|c|c|c|c|}
\hline & $\begin{array}{l}\% \text { of } \\
\text { experts }^{\mathrm{a}}\end{array}$ & $95 \% \mathrm{CI}$ & $\begin{array}{l}\text { Range- } \\
\text { regions }\end{array}$ & $\begin{array}{l}\text { Range- } \\
\text { experience }\end{array}$ \\
\hline \multicolumn{5}{|c|}{ Subaxial cervical spine (C3-C7) } \\
\hline None & 6.5 & $2.8-11.1$ & $0.0-8.7$ & $5.4-7.7$ \\
\hline Method 1 & 55.6 & $46.3-63.9$ & $46.4-60.9$ & $48.7-65.6$ \\
\hline Method 2 & 4.6 & $0.9-9.3$ & $0.0-10.7$ & $0.0-10.8$ \\
\hline Method 3 & 8.3 & $3.7-13.9$ & $0.0-11.8$ & $3.1-10.8$ \\
\hline Method 4 & 20.4 & $13.0-28.7$ & $8.3-47.1$ & $6.3-28.2$ \\
\hline Method 5 & 21.3 & $13.0-29.6$ & $5.9-41.7$ & $10.8-31.3$ \\
\hline Other & 0.9 & $0.0-2.8$ & $0.0-3.6$ & $0.0-2.6$ \\
\hline \multicolumn{5}{|c|}{ Thoracic spine (T1-T10) } \\
\hline None & 3.7 & $0.9-7.5$ & $0.0-8.3$ & $0.0-7.1$ \\
\hline Method 1 & 75.7 & $67.3-83.2$ & $40.0-80.0$ & $67.9-80.8$ \\
\hline Method 2 & 4.7 & $0.9-9.3$ & $0.0-10.3$ & $0.0-7.7$ \\
\hline Method 3 & 0.9 & $0.0-2.8$ & $0.0-4.2$ & $0.0-1.9$ \\
\hline Method 4 & 9.3 & $4.7-15.0$ & $6.7-20.0$ & $7.1-11.5$ \\
\hline Method 5 & 18.7 & $12.1-27.1$ & $8.3-40.0$ & $7.7-29.6$ \\
\hline Other & 0.9 & $0.0-2.8$ & $0.0-3.3$ & $0.0-3.6$ \\
\hline \multicolumn{5}{|c|}{ Thoracolumbar junction (T11-L2) } \\
\hline None & 4.7 & $0.9-9.3$ & $0.0-8.3$ & $0.0-7.1$ \\
\hline Method 1 & 72.0 & $63.6-80.4$ & $50.0-79.2$ & $60.7-76.9$ \\
\hline Method 2 & 8.4 & $2.8-14.0$ & $0.0-12.5$ & $3.7-11.5$ \\
\hline Method 3 & 1.9 & $0.0-4.7$ & $0.0-8.3$ & $0.0-3.6$ \\
\hline Method 4 & 13.1 & $7.5-19.6$ & $0.0-30.0$ & $11.1-17.9$ \\
\hline Method 5 & 15.0 & $9.3-22.4$ & $6.7-24.1$ & $7.7-22.2$ \\
\hline Other & 0.9 & $0.0-2.8$ & $0.0-3.3$ & $0.0-3.6$ \\
\hline \multicolumn{5}{|c|}{ Lumbar spine (L3-L5) } \\
\hline None & 6.5 & $1.9-11.2$ & $0.0-10.3$ & $0.0-7.1$ \\
\hline Method 1 & 71.0 & $61.7-79.4$ & $40.0-83.3$ & $67.9-73.1$ \\
\hline Method 2 & 7.5 & $2.8-13.1$ & $0.0-10.3$ & $3.7-9.6$ \\
\hline Method 3 & 0.9 & $0.0-2.8$ & $0.0-4.2$ & $0.0-3.6$ \\
\hline Method 4 & 11.2 & $5.6-17.8$ & $4.2-20.0$ & $7.4-13.5$ \\
\hline Method 5 & 17.8 & $11.2-25.2$ & $8.3-40.0$ & $9.6-29.6$ \\
\hline Other & 0.9 & $0.0-2.8$ & $0.0-3.3$ & $0.0-3.6$ \\
\hline
\end{tabular}

Relative frequencies are shown, along with their $95 \%$ bootstrapped confidence intervals (CI), and range among the different world regions (range, regions) and different degrees of experience (range, experience)

a The total percentage exceeds $100 \%$ as a combination of measurement techniques was indicated by some participants

for the subanalyses, the results presented are for the total responders from each survey $(n=107$ for TL-survey and $n=108$ for C-survey). The socio-demographic characteristics of the participants are shown in Table 1 .

\section{Measurement techniques}

As shown in Fig. 3 and Table 2, the Cobb method (Method 1) was the most frequently used technique for all spine regions to assess fracture kyphosis, although considerably less frequent for the subaxial cervical spine (55.6\%)

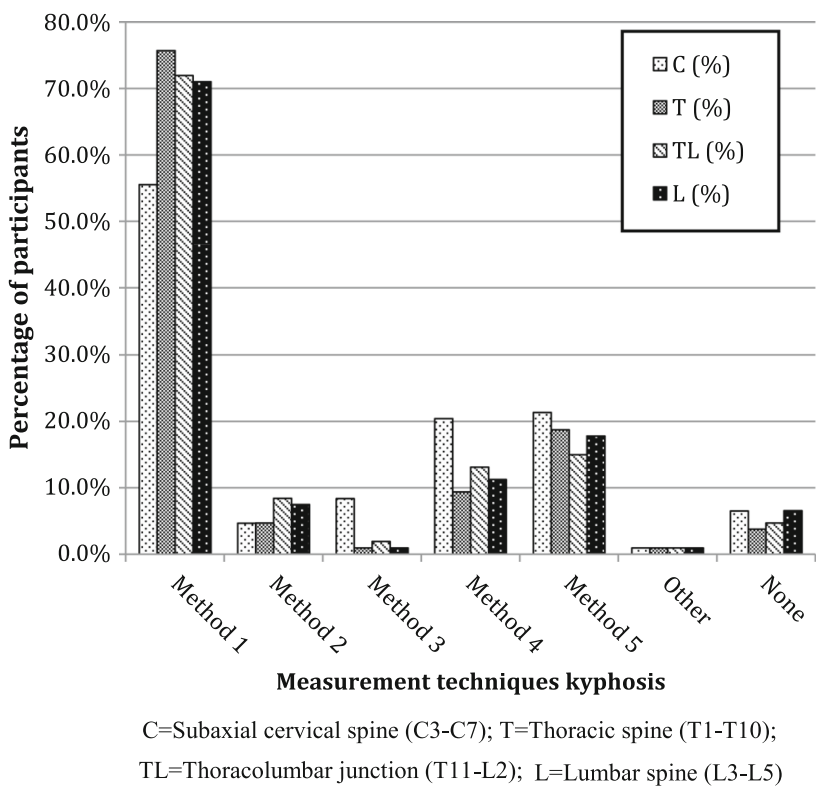

Fig. 3 Measurement techniques used by the percentage of experts to assess fracture kyphosis. $C$ subaxial cervical spine (C3-C7); $T$ thoracic spine (T1-T10); $T L$ thoracolumbar junction (T11-L2); $L$ lumbar spine (L3-L5)

compared with the other spine regions (71.0-75.7 \%). Also the wedge angle (Method 5) was used by a considerable number of experts, followed by the adjacent endplates method (Method 4). The least frequently used method in the subaxial cervical spine was Gardner's method (Method 2; $4.6 \%$ ), while the posterior walls method (Method 3) in the thoracic $(0.9 \%)$, thoracolumbar $(1.9 \%)$, and lumbar spine $(0.9 \%)$. In both surveys, only one expert indicated to use another technique to assess kyphosis. These were not the same participants. In the C-survey, the other technique was 'measuring from the superior endplates of the cephalad and caudad vertebral body'. In the TL-survey, 'T2 superior endplate to T10 inferior endplate' was the other measurement technique in the thoracic spine, 'T10 superior endplate to L2 inferior endplate' in the thoracolumbar junction, and 'L3 superior endplate to sacrum superior endplate' in the lumbar spine.

The results of the measurement techniques used to assess VBHL are shown in Fig. 4 and Table 3. The majority of the experts used the VBCR (Method 1) in all spine regions (51.4-54.6\%). Compared to kyphosis, a larger proportion of participants indicated not to measure VBHL (range among spine regions: 13.0-15.9\%). No participant used a different technique to assess VBHL.

All identified combinations of techniques to assess kyphosis along with their absolute and relative frequencies are shown in Table 4, as well as for the combination of VBCR and AVBC \% for VBHL. In total, 13 combinations of measurement techniques for kyphosis were identified, 


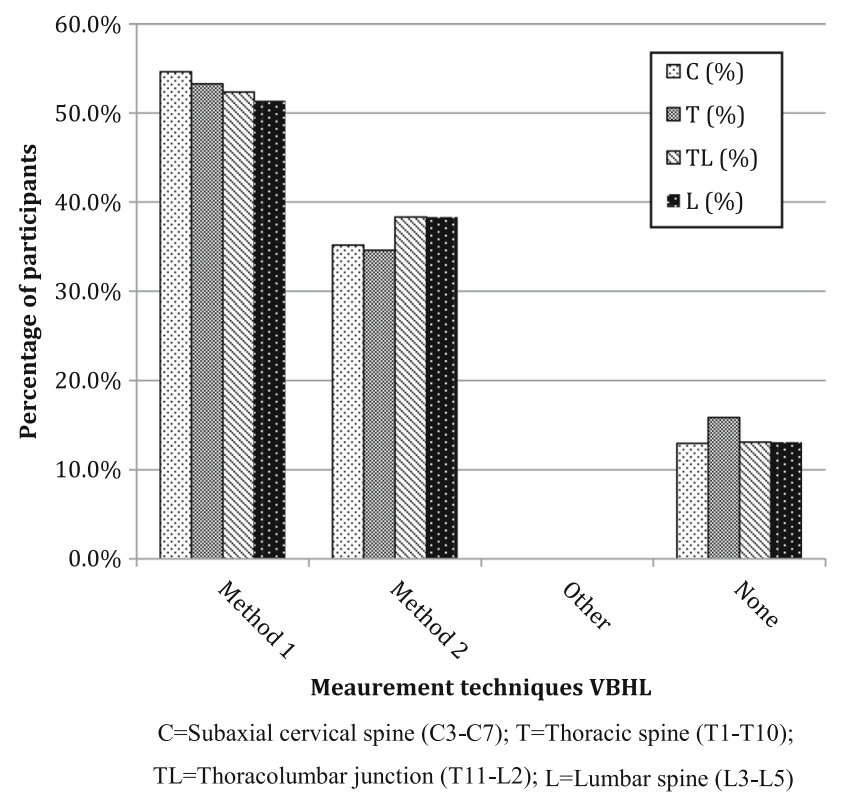

Fig. 4 Measurement techniques used by the percentage of experts to assess vertebral body height loss. $C$ subaxial cervical spine (C3-C7); $T$ thoracic spine (T1-T10); TL thoracolumbar junction (T11-L2); $L$ lumbar spine (L3-L5) but the most frequently used combination for all spinal regions was the assessment of the Cobb and wedge angles. Only 3 surgeons $(2.8 \%)$ indicated to use a combination of VBCR and AVBC \% to assess VBHL.

\section{Regional differences}

Analysis of the responses according to each world region showed that fracture kyphosis was most frequently assessed using the Cobb method. It was remarkable that for the subaxial cervical spine, the adjacent endplates method was considerably more often used by North American participants $(47.1 \%)$ compared to the other world regions (8.3-21.4\%; $p=0.069)$. For the thoracic spine, the Cobb method was less frequently used in the Middle East/North Africa (40.0 vs. 78.6-80.0\%; $p=0.155$ ), while the wedge angle was more often used (40.0 vs. 8.3-27.3\%; $p=0.145)$. Comparable patterns of regional variations were seen for the thoracolumbar junction and lumbar spine. The only significant difference between the world regions was the adjacent endplates method not being used by Asian participants, while $30 \%$ of the Middle East/North African
Table 3 Results for the assessment of vertebral body height loss

\begin{tabular}{lclcc}
\hline \multicolumn{1}{c}{$\%$ of experts $^{\mathrm{a}}$} & $95 \%$ CI & Range-regions & Range-experience \\
\hline Subaxial cervical spine (C3-C7) & & & \\
None & 13.0 & $7.4-19.4$ & $0.0-25.0$ & $6.3-20.5$ \\
Method 1 & 54.6 & $45.4-63.9$ & $42.9-83.3$ & $51.3-56.8$ \\
Method 2 & 35.2 & $26.9-45.4$ & $17.9-47.1$ & $32.4-40.6$ \\
Other & 0.0 & na & $0.0-0.0$ & $0.0-0.0$ \\
Thoracic spine (T1-T10) & & & \\
None & 15.9 & $9.3-23.4$ & $0.0-30.0$ & $10.7-21.2$ \\
Method 1 & 53.3 & $43.9-62.6$ & $40.0-64.3$ & $44.2-66.7$ \\
Method 2 & 34.6 & $26.2-43.9$ & $27.6-50.0$ & $25.9-39.3$ \\
Other & 0.0 & na & $0.0-0.0$ & $0.0-0.0$ \\
Thoracolumbar junction (T11-L2) & & & $3.6-19.2$ \\
None & 13.1 & $7.5-19.6$ & $0.0-20.7$ & $40.4-66.7$ \\
Method 1 & 52.3 & $43.0-60.7$ & $40.0-64.3$ & $25.9-42.9$ \\
Method 2 & 38.3 & $29.0-46.7$ & $27.6-50.0$ & $0.0-0.0$ \\
Other & 0.0 & na & $0.0-0.0$ & $3.6-19.2$ \\
Lumbar spine (L3-L5) & & & $38.5-66.7$ \\
None & 13.1 & $7.5-19.6$ & $0.0-20.0$ & $25.9-42.9$ \\
Method 1 & 51.4 & $42.1-60.7$ & $40.0-64.3$ & $0.0-0.0$ \\
Method 2 & 38.3 & $29.0-47.7$ & $27.6-50.0$ & $0.0-0.0$ \\
Other & 0.0 & na & & \\
\hline Relative & & & & \\
\hline
\end{tabular}

Relative frequencies are shown, along with their $95 \%$ bootstrapped confidence intervals $(\mathrm{CI})$, and range among the different world regions (range, regions) and different degrees of experience (range, experience) na not applicable

a The total percentage exceeds $100 \%$ as a combination of measurement techniques was indicated by some participants 
Table 4 Absolute and relative frequencies (\%) are shown for the identified combinations of measurement techniques used in each spine region for the assessment of fracture kyphosis and vertebral body height loss

\begin{tabular}{lllll}
\hline & $\mathrm{C}$ & $\mathrm{T}$ & $\mathrm{TL}$ & $\mathrm{L}$ \\
\hline Kyphosis & & & & \\
Methods 1 and 2 & $2(1.9)$ & $1(0.9)$ & $3(2.8)$ & $2(1.9)$ \\
Methods 1 and 3 & $2(1.9)$ & $1(0.9)$ & $1(0.9)$ & 0 \\
Methods 1 and 4 & $1(0.9)$ & $1(0.9)$ & 0 & 0 \\
Methods 1 and 5 & $7(6.5)$ & $8(7.5)$ & $6(5.6)$ & $5(4.7)$ \\
Methods 2 and 3 & $1(0.9)$ & 0 & 0 & 0 \\
Methods 2 and 4 & $1(0.9)$ & 0 & 0 & 0 \\
Methods 3 and 4 & $1(0.9)$ & 0 & 0 & 0 \\
Methods 3 and 5 & $1(0.9)$ & 0 & 0 & $1(0.9)$ \\
Methods 4 and 5 & 0 & $1(0.9)$ & $1(0.9)$ & $1(0.9)$ \\
Methods 1, 2 and 5 & 0 & $1(0.9)$ & 0 & $1(0.9)$ \\
Methods 1, 4 and 5 & 0 & 0 & $1(0.9)$ & $1(0.9)$ \\
Methods 1, 2, 3 and 5 & 0 & 0 & $13(12.1)$ & $11(10.3)$ \\
Methods 1, 3, 4 and 5 & $1(0.9)$ & $13(12.1)$ & $3(2.8)$ & $3(2.8)$ \\
Total & $17(15.7)$ & $3(2.8)$ & & 0 \\
VBHL & $3(2.8)$ & $T$ thoracic spine (T1-T10), TL thoracolumbar junction (T11-L2), \\
Methods 1 and 2 & & &
\end{tabular}

participants indicated to use this technique in the thoracolumbar junction ( $p=0.026)$.

Compared to fracture kyphosis, more regional variations were seen in the responses to VBHL. The VBCR method was more frequently used for the subaxial cervical spine by participants from all world regions, except for Latin American participants using more often the AVBC \% method (53.6 vs. $42.9 \%$ ). Moreover, a wide range was observed for VBCR method (42.9-83.3\%; $p=0.169$ ). Significant regional differences were seen for AVBC \% method (17.9-53.6 \%; $p=0.047)$, and for not measuring VBHL $(0.0-25.0 \% ; p=0.044)$. Also in the thoracic, thoracolumbar and lumbar spine, the VBCR method seemed to be more frequently used than the AVBC \% method, except for Middle East/North Africa using the latter more frequently in the thoracolumbar and lumbar spine (both 50 vs. $40 \%$ ).

\section{Influence of experience}

Fewer differences were observed when taking the spine surgeons' degree of clinical experience into account. Regardless of the experience, most surgeons used the Cobb method to assess kyphosis in all spine regions. In the subaxial cervical spine, some variations were seen for the adjacent endplates method $(6.3-28.2 \% ; p=0.043)$ and the wedge angle method $(10.8-31.3 \% ; p=0.113)$.

Concerning the measurement techniques to assess VBHL in the subaxial cervical spine, the VBCR method was used by most surgeons in all subgroups of clinical experience. More variation was observed for the measurement techniques in the thoracic, thoracolumbar and lumbar spine, with the only significant differences for using the VBCR method in the thoracolumbar junction $(40.4-66.7 \% ; p=0.049)$ and lumbar spine $(38.5-66.7 \% ; p=0.031)$.

\section{Comments}

No general comments concerning the measurement techniques were provided by the participants.

\section{Discussion}

To the best of our knowledge, this is the first study exploring the measurement techniques preferred by a worldwide sample of spine trauma experts to assess traumatic fracture kyphosis and vertebral body height loss. In the only previous study performed by the Spine Trauma Study Group, a small number of 35 member surgeons were surveyed on the methods used for assessing kyphosis [23]. However, the main objective of that study was to provide an updated definition of post-traumatic kyphosis, and methods for diagnosis and treatment of post-traumatic kyphosis, rather than to survey the preferred method to measure fracture kyphosis.

Including 107 spine surgeons from 43 different countries in the first survey (TL survey), and 108 from 41 
different countries in the second survey (C-survey), the results from this study are considered as a valid reflection of the current practice in spine trauma care worldwide.

The most frequently indicated technique to assess fracture kyphosis was measuring the Cobb angle (Method 1), followed by the wedge angle (Method 5). Kuklo et al. investigated the inter- and intra-rater reliability of the same five measurement techniques for kyphosis as we surveyed, and concluded that the Cobb method showed the best intraand inter-observer reliability, followed by the wedge angle [24]. Also in the aforementioned survey by the Spine Trauma Study Group [23], the same Cobb angle was reported to be most useful in measuring kyphosis. One other study investigated the influence of experience on reproducibility of kyphosis measurement among physicians with different degrees of experience [25]. This study found the methods not taking the fractured vertebra into account to be the most reproducible. These methods are the same as Method 1 (Cobb angle) and Method 4 (adjacent endplates method) in the current study. The posterior walls angle method (Method 3) was least frequently used. With this method, the exact location of the vertebral body may be difficult to establish. No 'gold standard' or 'true value' exists for measuring kyphosis or VBHL, but the aforementioned studies demonstrate the most satisfactory results for the Cobb angle to assess fracture kyphosis. Compared to the other measurement techniques surveyed in the current study, a larger area over which to measure is included when using this bisegmental measurement method. The potential advantages are the minimization of differences between measurements as well as the recognition of the degree of instability of the injured spinal segment.

It is worth mentioning that many studies investigating kyphosis measurement techniques only focus on the thoracic and lumbar spine [23-26]. Moreover, those studies were performed in a single center or small group setting, which makes them subjective to bias and less representative for a worldwide perspective. We investigated the preferred measurement techniques for the entire spinal column, except for the occipitocervical junction $(\mathrm{C} 0-\mathrm{C} 2)$. The anatomy and biomechanical properties of this spine region are substantially different compared to the other regions. Very specific and useful measurement techniques for this spine region have been described in the Radiographic Measurement Manual of the Spine Trauma Study Group [22].

Concerning vertebral body height loss, the VBCR method was most frequently used by the surveyed experts. This is a useful method to assess the structural integrity of the fractured vertebral body, specifically, that of the anterior and middle columns of the injured vertebra. Interestingly, based on the results of a systematic literature review, the Spine Trauma Study Group recommended to routinely use the AVBC \% method to assess VBHL [26]. We think that additional reliability studies are needed to substantiate such recommendations.

We do recognize several limitations of this study. First, the survey was incorporated in two other planned surveys and therefore sent on two separate occasions. This may have led to some bias when comparing the results from the two occasions. Second, the surveys were sent to a selected pool of spine surgeons. However, we believe we were able to reach a representative international sample of highly experienced spine trauma experts.

In conclusion, this study identified worldwide variations in measurement techniques preferred by treating spine surgeons to assess fracture kyphosis and vertebral body height loss in spine trauma patients. These results confirm our hypothesis that a standardized technique is currently not employed. For clinical purposes, and to provide meaningful comparisons among study reports, it is recommended to use validated tools and standardized assessment parameters. The AOSpine Knowledge Forum Trauma endorses the use of universal methods and techniques, and initiated projects to develop classification systems for spine injuries, as well as disease-specific outcome instruments for spine trauma patients [27]. The results obtained from the current study establish the importance of standardization of assessment parameters in spine trauma care, and can be taken into account to further investigate these radiographic parameters in the process toward a universal language.

\section{Compliance with ethical standards}

Conflict of interest AOSpine is a clinical division of the AO Foundation-an independent medically guided nonprofit organization.

The AOSpine Knowledge Forums are pathology focused working groups acting on behalf of AOSpine in their domain of scientific expertise. Each forum consists of a steering committee of up to 10 international spine experts who meet on a regular basis to discuss research, assess the best evidence for current practices, and formulate clinical trials to advance spine care worldwide. Study support is provided directly through AOSpine's Research department.

Open Access This article is distributed under the terms of the Creative Commons Attribution 4.0 International License (http://crea tivecommons.org/licenses/by/4.0/), which permits unrestricted use, distribution, and reproduction in any medium, provided you give appropriate credit to the original author(s) and the source, provide a link to the Creative Commons license, and indicate if changes were made.

\section{References}

1. Roche SJ, Sloane PA, McCabe JP (2008) Epidemiology of spine trauma in an Irish regional trauma unit: a 4-year study. Injury 39:436-442. doi:10.1016/j.injury.2007.12.012 
2. Hu R, Mustard CA, Burns C (1996) Epidemiology of incident spinal fracture in a complete population. Spine 21:492-499

3. Pickett W, Simpson K, Walker J, Brison RJ (2003) Traumatic spinal cord injury in Ontario, Canada. J Trauma 55:1070-1076. doi:10.1097/01.TA.0000034228.18541.D1

4. Blumer CE, Quine S (1995) Prevalence of spinal cord injury: an international comparison. Neuroepidemiology 14:258-268

5. Wyndaele M, Wyndaele JJ (2006) Incidence, prevalence and epidemiology of spinal cord injury: what learns a worldwide literature survey? Spinal cord 44:523-529. doi:10.1038/sj.sc. 3101893

6. Vaccaro AR, Lim MR, Hurlbert RJ, Lehman RA Jr, Harrop J, Fisher DC, Dvorak M, Anderson DG, Zeiller SC, Lee JY, Fehlings MG, Oner FC (2006) Surgical decision making for unstable thoracolumbar spine injuries: results of a consensus panel review by the Spine Trauma Study Group. J Spinal Disord Tech 19:1-10. doi:10.1097/01.bsd.0000180080.59559.45

7. Patel AA, Hurlbert RJ, Bono CM, Bessey JT, Yang N, Vaccaro AR (2010) Classification and surgical decision making in acute subaxial cervical spine trauma. Spine 35:S228-S234. doi:10. 1097/BRS.0b013e3181f330ae

8. Stiell IG, Wells GA, Vandemheen KL, Clement CM, Lesiuk H, De Maio VJ, Laupacis A, Schull M, McKnight RD, Verbeek R, Brison R, Cass D, Dreyer J, Eisenhauer MA, Greenberg GH, MacPhail I, Morrison L, Reardon M, Worthington J (2001) The Canadian C-spine rule for radiography in alert and stable trauma patients. JAMA 286:1841-1848

9. Vaccaro AR, Schroeder GD, Kepler CK, Cumhur Oner F, Vialle LR, Kandziora F, Koerner JD, Kurd MF, Reinhold M, Schnake KJ, Chapman J, Aarabi B, Fehlings MG, Dvorak MF (2016) The surgical algorithm for the AOSpine thoracolumbar spine injury classification system. Eur Spine J 25(4):1087-1094. doi:10.1007/ s00586-015-3982-2

10. Joaquim AF, Ghizoni E, Tedeschi H, Batista UC, Patel AA (2014) Clinical results of patients with thoracolumbar spine trauma treated according to the Thoracolumbar Injury Classification and Severity Score. J Neurosurg Spine 20:562-567. doi:10. 3171/2014.2.SPINE121114

11. Hiyama A, Watanabe M, Katoh H, Sato M, Nagai T, Mochida J (2015) Relationships between posterior ligamentous complex injury and radiographic parameters in patients with thoracolumbar burst fractures. Injury 46:392-398. doi:10.1016/j.injury.2014. 10.047

12. Pneumaticos SG, Karampinas PK, Triantafilopoulos G, Koufos S, Polyzois V, Vlamis J (2015) Evaluation of TLICS for thoracolumbar fractures. Eur Spine J 25(4):1123-1127. doi:10.1007/ s00586-015-3889-y

13. Chadha M, Bahadur R (1998) Steffee variable screw placement system in the management of unstable thoracolumbar fractures: a Third World experience. Injury 29:737-742

14. McAfee PC, Yuan HA, Fredrickson BE, Lubicky JP (1983) The value of computed tomography in thoracolumbar fractures. An analysis of one hundred consecutive cases and a new classification. J Bone Joint Surg Am 65:461-473

15. Mikles MR, Stchur RP, Graziano GP (2004) Posterior instrumentation for thoracolumbar fractures. J Am Acad Orthop Surg 12:424-435

16. Verheyden AP, Holzl A, Ekkerlein H, Gercek E, Hauck S, Josten C, Kandziora F, Katscher S, Knop C, Lehmann W, Meffert R, Muller CW, Partenheimer A, Schinkel C, Schleicher P, Schnake
KJ, Scholz M, Ulrich C (2011) Recommendations for the treatment of thoracolumbar and lumbar spine injuries. Der Unfallchirurg 114:9-16. doi:10.1007/s00113-010-1934-1

17. Siebenga J, Leferink VJ, Segers MJ, Elzinga MJ, Bakker FC, Haarman HJ, Rommens PM, ten Duis HJ, Patka P (2006) Treatment of traumatic thoracolumbar spine fractures: a multicenter prospective randomized study of operative versus nonsurgical treatment. Spine 31:2881-2890. doi:10.1097/01.brs. 0000247804.91869.1e

18. Vaccaro AR, Kim DH, Brodke DS, Harris M, Chapman JR, Schildhauer T, Routt ML, Sasso RC (2004) Diagnosis and management of thoracolumbar spine fractures. Instr Course Lect 53:359-373

19. Korovessis P, Baikousis A, Zacharatos S, Petsinis G, Koureas G, Iliopoulos $\mathrm{P}$ (2006) Combined anterior plus posterior stabilization versus posterior short-segment instrumentation and fusion for mid-lumbar (L2-L4) burst fractures. Spine 31:859-868. doi:10. 1097/01.brs.0000209251.65417.16

20. Sadiqi S, Verlaan JJ, Lehr AM, Dvorak MF, Kandziora F, Rajasekaran S, Schnake KJ, Vaccaro AR, Oner FC (2016) Surgeon reported outcome measure for spine trauma an international expert survey identifying parameters relevant for the outcome of subaxial cervical spine injuries. Spine (Phila Pa 1976). doi:10. 1097/BRS.0000000000001683

21. Sadiqi S, Verlaan JJ, Lehr AM, Dvorak MF, Kandziora F, Rajasekaran S, Schnake KJ, Vaccaro AR, Oner FC (2016) Universal disease-specific outcome instruments for spine trauma - a global perspective on relevant parameters to evaluate clinical and functional outcomes of thoracic and lumbar spine trauma patients. Eur Spine J (Epub ahead of print)

22. Kuklo TR, Bono CM, Dimar JR, Rauschning WE, Vaccaro AR (2004) Radiographic measurement manual. Spine Trauma Study Group

23. Schoenfeld AJ, Wood KB, Fisher CF, Fehlings M, Oner FC, Bouchard K, Arnold P, Vaccaro AR, Sekhorn L, Harris MB, Bono CM (2010) Posttraumatic kyphosis: current state of diagnosis and treatment: results of a multinational survey of spine trauma surgeons. J Spinal Disord Tech 23:e1-e8. doi:10.1097/ BSD.0b013e3181c03517

24. Kuklo TR, Polly DW, Owens BD, Zeidman SM, Chang AS, Klemme WR (2001) Measurement of thoracic and lumbar fracture kyphosis: evaluation of intraobserver, interobserver, and technique variability. Spine 26:61-65 (discussion 66)

25. Alvarenga JA, Martins DE, Ueta RH, Del Curto D, Wajchenberg M, Puertas EB (2014) Impact of surgeons' experience on accuracy of radiographic segmental kyphosis assessment in thoracolumbar fractures: a prospective observational study. Patient Saf Surg 8:15. doi:10.1186/1754-9493-8-15

26. Keynan O, Fisher CG, Vaccaro A, Fehlings MG, Oner FC, Dietz J, Kwon B, Rampersaud R, Bono C, France J, Dvorak M (2006) Radiographic measurement parameters in thoracolumbar fractures: a systematic review and consensus statement of the spine trauma study group. Spine 31:E156-E165. doi:10.1097/01.brs. 0000201261.94907.0d

27. AOSpine/AOSpine Knowledge Forums/Trauma/Outcome measurement. AO Spine. https://aospine.aofoundation.org/Structure/ research/KnowledgeForum/Pages/knowledge-forum.aspx. Accessed 10 Feb 2016 